\title{
VIOLENCE IS NOT CONFLICT: Why it Matters in Restorative Justice Practice
}

\author{
ALAN EDWARDS* $^{*}$ AND JENNIFER HASLETT ${ }^{* *}$
}

The rapid growth of restorative justice programs calls for greater self-reflection and a higher standard of practice in the restorative justice field. This article addresses the distinction between violence and conflict, and the significant implications of this difference, in the restorative justice process. It offers insight into violence and victimization and sets out a number of approaches beneficial to helping solidify these important distinctions and in linking explanations to practice. Failure to understand violence and conflict as distinct concepts may potentially leave people and communities at risk of further harm.
La croissance rapide des programmes de justice réparatrice nous amène à réfléchir davantage à une meilleure norme de pratique dans ce domaine. Cet article aborde la distinction entre violence et conflit et les importantes répercussions de cette différence dans le domaine de la justice réparatrice. $L$ 'article jette une lumière sur la violence et la victimisation, présente quelques approches utiles pour aider à solidifier ces différences importantes et à faire le lien entre les explications et la pratique. Le fait de ne pas comprendre la distinction entre violence et conflit peut potentiellement présenter un risque de préjudice aux individus et aux communautés.

\section{TABLE OF CONTENTS}

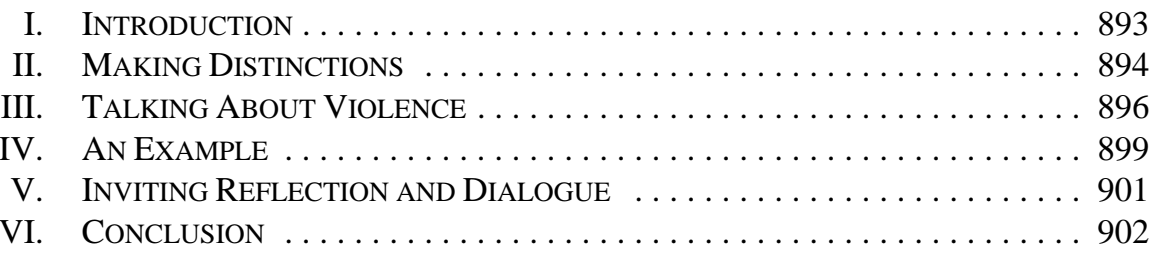

\section{INTRODUCTION}

Violence is not ... simply an escalation in conflict. It is categorically different. It is one thing to have a difference of opinion and to argue. It is quite another to attack another physically. ${ }^{1}$

The rapid growth of restorative justice programs regionally, nationally, and globally has certainly been an ongoing cause for celebration among restorative justice practitioners and supporters, and for good reason. The oft-touted values of the restorative justice approach invite a serious reconsideration of what a just response to harm and crime might need to include, as well as a challenge to historical norms regarding whose voices need to be heard

* $\quad$ Restorative justice practitioner, mediator, and instructor based in Edmonton, Alberta. Since 1997, Alan has maintained an active private practice in workplace mediation alongside his work in restorative justice, which focuses almost exclusively on cases involving violence. Starting in 2004, he has been cofacilitating with Jennifer Haslett cases in Canada's prairie provinces that involve serious and violent crime. He has delivered workshops and training in restorative justice throughout Canada and the United States. He is co-author of four papers about restorative justice and violence.

** B.A. (Alberta). Jennifer has been a practitioner and consultant in the fields of restorative justice and conflict resolution since 1996. She has been a restorative justice facilitator with the Restorative Opportunities Program of the Correctional Service of Canada since 2004. Prior to that, she coordinated a victim-offender mediation program for six years. She has co-instructed the Critical Issues in Restorative Justice course at the University of Alberta, and has been an active member of a national restorative justice steering committee for five years.

1 Howard Zehr, Changing Lenses: A New Focus for Crime and Justice (Scottsdale, Pa.: Herald Press, 1990) at 183. Here, Zehr is summarizing a distinction voiced by author Marie Marshall Fortune at a 1986 restorative justice gathering. 
in the pursuit of justice, including victims, offenders, and community members. More than this, restorative justice signals an opportunity to breathe new life into the concept of justice itself.

At the same time, the din from this celebration risks muting the sound of critical voices that call for, among other things, greater self-reflection and a higher standard of practice in the restorative justice field. As restorative justice programs increase in number, the demands on those programs have similarly increased, with the result that programs and practitioners are more often being tasked with facilitating cases involving interpersonal violence, including situations of family violence and sexualized violence. This can create a gap between what facilitators are prepared for and what is being requested of them.

Our work in restorative justice dates back to 1998, when we became active as practitioners in victim-offender mediation in Edmonton, Alberta. Since 2004, we have been working as facilitators in cases of serious and violent crime. Most of our cases involve the loss of life as a result of violence. The fatalities and assaults may occur in intimate relationships, in the workplace, in gangs, or between strangers or friends. The weapons involved may include guns, knives, hands, penises, or the seemingly infinite number of objects that can inflict wounds. What remains a constant in our cases is the use of violence.

\section{MAKING Distinctions}

An observation we have made is that "conflict" and "violence" have become concepts that are used interchangeably when restorative justice practitioners think about and practice their work. It is our belief that this practice has the potential to leave people and communities at risk of further harm. This article uses the term "conflict" to signify interpersonal conflict. Our intention is not to bring focus to issues surrounding "inner conflict" or "international conflict," even though distinguishing conflict from violence is relevant in the international arena.

We recognize that various definitions of violence make room for behaviours that are in addition to physical force. Terms like emotional violence, psychological violence, and verbal violence become meaningful in some definitions of violence, but meaningless in others. While we assert that it is important for restorative justice practitioners to be clear about their own definition of what constitutes violence, we deliberately refer only to physical violence in this article. We also suggest that it is crucial to distinguish violence from conflict, and that doing so will enable restorative justice practitioners, participants, and communities to create and engage in safer and more informative restorative justice processes that more effectively assist people in the aftermath of physical violence. We further recognize from our casework that, just as it is the case that conflict can exist without any violence occurring, violence can exist without the presence of conflict.

One of the difficulties inherent in making this assertion is that, in the restorative justice field, there is no agreed-upon definition for either violence or conflict. Contributing to this confusion is the backdrop of great and long-lasting debates about an accurate definition for restorative justice. However, the scope of this article makes it impossible to set out the various perspectives surrounding definitions of, motivations for, or causes of interpersonal 
conflict or interpersonal violence. Theories of violence can differ greatly depending on the emphasis that they put on biological, psychological, or social/environmental factors.

The fields of conflict resolution, psychology, and criminology illuminate important differences between conflict and violence. We draw from theories of conflict that view conflict as a state or condition of being. For example, the standard definition of conflict in transformative mediation is that it represents a crisis in human interaction. ${ }^{2}$ In narrative mediation, conflict "can be understood as a clash of entitlements that occurs between individuals or groups in overt or covert ways on a day-to-day basis." ${ }^{3}$ Under this interpretation, crises and clashes represent conditions of being.

These definitions also stress conflict's fundamental interactivity: ${ }^{4}$ conflict involves the active participation of two or more disputants, both or all of whom share some responsibility for the creation and continuation of a conflict. Violence lacks this interactive dimension, even when two people are being violent toward each other. Much of the research and theory that undergirds our work sees violence as unidirectional; ${ }^{5}$ the violent act is committed unilaterally by one person against the will and well-being of another. Further, research into the consequences of using violence in intimate relationships demonstrates that, rather than violence being a conflict resolution action, it instead serves as a conflict removal action. ${ }^{6}$ Ruth Busch, in reference to a comment from a domestic violence worker, observes that, "rather than an escalation in conflict, the use of violence by a party often suppresses the conflict."7

This distinction between resolution and removal/suppression resonates with the overwhelming majority of those cases that we have experienced in which violence arose out of conflict, regardless of whether the case fits within the narrow parameters of being a domestic violence case.

Conflicts can, of course, be very difficult, complex, and accompanied by a range of powerful emotions and impacts. Conflicts can also be the start of healthy opportunities to discover difference and diversity, grow in our understanding of the world, and be used as catalysts for new and creative ways of thinking. In fact, one could argue that they are essential to a thriving democracy. Violence does not offer these opportunities.

Robert A. Baruch Bush \& Joseph P. Folger, The Promise of Mediation: Responding to Conflict Through Empowerment and Recognition (San Francisco: Jossey-Bass, 1994) at 191-92.

3 John Winslade \& Gerald Monk, Narrative Mediation: A New Approach to Conflict Resolution (San Francisco: Jossey-Bass, 2000) at 96.

$4 \quad$ See e.g. Joseph P. Folger, Marshall Scott Poole \& Randall K. Stutman, Working Through Conflict: Strategies for Relationships, Groups, and Organizations, 5th ed. (Boston: Pearson Education, 2005) at 4, where the definition of conflict begins with the words "[c]onflict is the interaction of interdependent people." They then state that "[t]he most important feature of conflict is based in interaction" [emphasis added].

$5 \quad$ See especially Linda Coates \& Allan Wade, "[Language] and Violence: Analysis of Four Discursive Operations" (2007) 22 Journal of Family Violence 511 at 513-14. See also Richard B. Felson, "Predatory and Dispute-Related Violence: A Social Interactionist Approach" in David P. Barash, ed., Understanding Violence (Toronto: Allyn \& Bacon, 2001) 260.

$6 \quad$ See Margareta Hydén, "Verbal Aggression as Prehistory of Woman Battering” (1995) 10 Journal of Family Violence 55 at 69. See also Randall Collins, Violence: A Micro-sociological Theory (Princeton, N.J.: Princeton University Press, 2008) at 346.

Ruth Busch, "Domestic Violence and Restorative Justice Initiatives: Who Pays if We Get It Wrong?" in Heather Strang \& John Braithwaite, eds., Restorative Justice and Family Violence (Cambridge: Cambridge University Press, 2002) 223 at 232. 
Cultural factors may account for the blurred lines between conflict and violence in restorative justice work. As with all definitions, our definitions and ideas about violence and conflict are socially constructed. That is, they are determined and influenced by location, and they change over time. Currently, mainstream North American ideas of these two concepts sometimes put them in overlapping proximity with each other, creating confusion. For example, one hears news reports regarding "violent conflict," “conflict escalating to violence," "armed conflict," and so on.

Violence seems most easily subsumed under the conflict umbrella in situations where it is obvious that conflict has existed prior to violence. For example, if a man breaks into a house and rapes a woman we are not as likely to speak of the "conflict" between them. However, in a situation where two people are arguing about money and one of them assaults the other, we are much more likely to see this merely as a conflict that "got out of hand.” It is important to look more closely at these kinds of characterizations and reflect on what our beliefs about conflict and violence really are.

In our view, seeing only conflict in the second scenario is to render the violence unseen and normalized. Certainly, however, if the violence were "normal" then there would be little or no need to address the injustice done or offer apology or repair. Nor would one seek to identify or challenge any social, environmental, or political conditions that may exist in that context which influence individual choices. And since many theories of violence recognize a confluence of internal and external factors as informing a person's choice to use violence, a conflict-focused approach to violence is likely to miss this complexity.

\section{Talking About Violence}

Anyone who has facilitated a restorative justice process would tell you that the theory of restorative justice looks much tidier on paper than it does when you are sitting in a room with people whose lives have been disrupted by violence and its aftermath. Looking at literature and theories from a variety of disciplines has helped us as we have sought to better understand what we were experiencing in our work with people.

Margareta Hydén, in her study of men’s accounts of violence against their intimate partners, writes about "conflict stories" and "violence stories." ${ }^{\text {" }}$ "She found that these men and women focused their conversations very differently when talking about the violence in their relationships. The men that she interviewed emphasized what provoked the violence (conflict stories) and skimmed over the violent acts, while the women concentrated on the violent acts and their consequences, "especially their feelings of powerlessness, fear, [and] of being 'mentally broken'” (violence stories). ${ }^{9}$ This has been something that we too have noticed in our restorative justice work. For the person who has committed the violence, their focus has often been on having the facilitators understand, in detail, their position in the conflict, or how the other person was behaving in a way that was unfair or unreasonable. For the person who has experienced the violence, we hear much more about the fear, shame, pain, and/or how the event(s) have altered the way that they think or behave. 
Hydén also describes the different interpretations of intent the men and women gave to the violent act(s). Women perceived that the intent of the violence was to harm them, and therefore considered it an assault. Men spoke of their intent to influence the women with respect to the verbal fight, which meant that it remained part of a reciprocal exchange. ${ }^{10}$

Treating violence as if it is conflict may also be an example of what is termed "hygienic positioning."11 "Violence" can seem daunting and uncomfortable to deal with when compared to "disagreements” or "misunderstandings.” Most of us find violence disturbing and, the closer our proximity to violence, the less comfortable we tend to become. Hygienic positioning is one response to this discomfort and involves "keeping oneself at a distance, physically and psychologically, from the violence and its victims, for example, by using disparaging terms for the victims or euphemisms for the violence."12 As this is a common behavioural response to violence, restorative justice practitioners are as likely to experience it as anyone else. When practitioners exhibit this behaviour, however, there are costs to both victims and offenders. ${ }^{13}$

When practitioners engage in hygienic positioning, several important changes will likely occur in the restorative justice process. When too uncomfortable to facilitate focused dialogue about violence, practitioners may decide to recast violence as "the disagreement" or "a communication problem"; the assault may morph into "the incident" or "the misunderstanding"; or, as one violent offender offered, "the unfortunate sequence of events." These linguistic shifts are about far more than wordsmithing, however. As Sara Cobb demonstrates, in cases such as these the violence itself becomes hidden and invisible. ${ }^{14}$ One consequence of hiding violence is that it becomes normalized by the facilitators' euphemistic avoidance of it; an ironic result of a process that is supposed to be harm-focused. This avoidance bears considerable resemblance to the kind of minimizing that offenders are often depicted as engaging in, and this in turn may create a process that is harmful to victims as their experiences of violence are not acknowledged or validated. ${ }^{15}$

Practitioners' language choices may also be influenced by ideas drawn from the field of conflict resolution, given that many practitioners come to restorative justice with this background/context. Restorative justice training often borrows heavily from mainstream

$10 \quad$ Ibid. at 66.

11 See Jack David Eller, Violence and Culture: A Cross-Cultural and Interdisciplinary Approach (Belmont, Calif.: Thomson Wadsworth, 2006) at 325-26. See also Arnold P. Goldstein, Violence in America: Lessons on Understanding the Aggression in Our Lives (Palo Alto, Calif.: Davies-Black, 1996) at 31-33. Eller, ibid. at 326.

We recognize the risks of using the terms “victim” and “offender.” Applying labels to people who have caused harm or who have experienced harm runs the risk of defining human beings on the basis of one (or more) event(s) in their lives, but we see this risk as existing irrespective of the labels used — "person harmed," "person who has offended," etc. The problem is not so much in the words used as in the thoughts and behaviour of the practitioner. We also recognize that the terms "victim" and "offender" rightly acknowledge the reality that one person was harmed at the hands of another person. We suggest that this issue encompasses far more than the arbitrary mechanics of choosing labels, and we invite further discussion about this topic.

14 Sara Cobb, “The Domestication of Violence in Mediation” (1997) 31 Law \& Soc’y Rev. 397.

15 For a detailed study of how thoughts about violence change when the language used to describe violence changes, see Nancy M. Henley, Michelle Miller \& Jo Anne Beazley "Syntax, Semantics, and Sexual Violence: Agency and the Passive Voice” (1995) 14 Journal of Language and Social Psychology 60. See also Janet Bavelas \& Linda Coates, "Is it Sex or Assault? Erotic Versus Violent Language in Sexual Assault Trial Judgments” (2001) 10 Journal of Social Distress and the Homeless 29. 
conflict resolution training: the use of active listening skills, "neutral”16 language to describe the "problem," reframing, ${ }^{17}$ and an assumption that facilitated dialogue should result in agreements. These imported ideas, as poorly suited as they might be to the task of engaging with violence narratives, constitute the verbal methodology of a great deal of restorative justice practice, particularly in victim-offender mediation.

In Cobb's research of discourse within mediation sessions, she observed how mediators' interventions contributed to violence being "domesticated" in 80 percent of the situations where violence stories appeared. ${ }^{18}$ Her definition of "domestication" refers to a movement from a "rights-based" discourse to a "need-based" discourse in the context of a mediation session. ${ }^{19}$ This is significant in that it highlights choices practitioners can make that can result in silencing the voices of victims and removing violence narratives as topics of discussion for participants. Cobb further notes that the domestication of violence occurred through:

(1) the reformulation of violence as unintentional (as accomplished by describing the victimizer as “confused," reframing violence as a "misunderstanding”); and (2) the reformulation of violence as

"confrontation" (victim/victimizer roles disappear as both parties are constructed as mutually contributing to the "conflict"). 20

One description of violence that we heard from an offender illustrates these reformulations well: "We were in conflict, one thing led to another and now he's dead." In collapsing the violence into the conflict the offender erased his agency regarding his violence. To be in conflict suggests shared responsibility, so that when "one thing led to another," the outcome risks being interpreted as a shared responsibility. "And now he's dead” speaks to the end point of the confrontation that Cobb refers to.

Allan Wade argues that "[i]n legal and therapeutic settings language is often used in a manner that obscures the unilateral and deliberate nature of violent acts." ${ }^{21}$ We would argue that this is also true in restorative justice work. Neutral phrases such as "when she got hurt," "when he fell," or "after the accident" can fail to accurately reflect intent in a violent act. This use of neutral language removes individual choice and agency concerning the use of violence.

"Neutral language" is a term used in some predominant approaches to conflict resolution. It refers to practitioners using language that will be perceived by disputants as non-blaming, non-positional, and not favouring one disputant's views over the other participant's views. For example, rather than a topic being called "Bob's ineffective contributions to the team," mediators would invite a topic like "teamwork" or "individual responsibilities to the team." These differences in language are viewed as making the conversations easier for all disputants to participate in without feeling blamed or judged.

"Reframing," in the interest-based approach to conflict resolution, refers to the activity of verbalizing, using positive rather than negative language, the needs and values that are relevant to the disputants as they relate to the conflict. For example, if a disputant is complaining that they are working too much and do not have enough time to spend with their family, the practitioner might respond with the reframe, "So, having a better work/life balance is important to you." A reframe "translates" negative language about what a person does not want/need into positive language about what they do need/value. Supra note 14 at 397.

Ibid. at 400 .

Ibid. at 426.

Allan Wade, “Despair, Resistance, Hope: Response-Based Therapy with Victims of Violence” in Carmel Flaskas, Imelda McCarthy \& Jim Sheehan, eds., Hope and Despair in Narrative and Family Therapy: Adversity, Forgiveness and Reconciliation (New York: Routledge, 2007) 63 at 73. 
Practitioner motivations for these linguistic choices may include the desire not to alienate or agitate participants, to appear impartial and non-judgmental in the role as facilitator, or to create a safe space for dialogue. And while these motivations are not intrinsically poor, it is important to pay attention to the alternative meanings and unintended consequences that may flow from linguistic choices. Victim advocates have consistently challenged restorative justice programs to see to it that victims' experiences of violence are accurately named and validated in order to ensure that victims do not suffer further harm.

\section{AN EXAMPLE}

How participants in a restorative justice process come to perceive the violence that they have experienced, whether committing it or suffering it, and what steps they choose to take will likely be determined, to a significant degree, by the orientation of the facilitators. Imagine a case involving an argument during which one person punched another person, knocking him out. We believe that if the facilitators, in their opening comments, frame the session along the lines of "We're here to help you sort out the incident where the two of you had a disagreement that escalated to violence," then the session will proceed on a different trajectory than if they had instead began by saying something like "We're here to assist you both in discussing Bill's use of violence against Chris, what led up to Bill making that choice, what Chris experienced in that moment and since, and also where you each might want to go from here.”

In the first scenario, the messages sent to the participants are that:

- what happened that day, both the violence and the conflict, are minor (note how the euphemism "incident" not only minimizes the significance of what occurred, but also makes the violence invisible);

- $\quad$ whatever happened in "the incident” is a conflict (“disagreement”);

- $\quad$ the participants are there to discuss a conflict; and

- the locus of the violence is their relationship and no one person is responsible for committing the violence (mutualizing the conflict that, as the facilitators see it, contains violence and placing the responsibility for "resolving" the violence on the two people in the relationship).

Here, violence is framed as part of both their relationship and their conflict and, implicit in the message, resolving the conflict will eliminate the risk of any future violence.

In the second scenario, the facilitators are sending different messages:

- the violence and its impacts are topics in and of themselves, distinct from whatever else was going on; 
- "what led up to Bill making that choice" is relevant and open for discussion (keeping in mind that what precedes Bill's use of violence may be conflict, and possibly previous violence as well);

- $\quad$ Bill's use of violence was a choice, even if it was influenced by external factors; and

- $\quad$ it is open for them to make decisions concerning the future.

If one sentence can change the nature and scope of a restorative justice session, imagine an entire session in which the facilitators continually sidestep the issue of violence (making it invisible), framing it instead as a disagreement or misunderstanding.

This might result in an agreement that sets out a resolution for the conflict without having identified reparation of any kind for the harms created in the wake of the violence. Offenders could also risk leaving a restorative justice session without a fuller understanding of the factors that influenced their choice to use violence or the extent of the impacts that their violence has had on others. If victims come to see the conflict as the cause of the violence, they may mistakenly believe that they are safe from a reoccurrence of violence once the conflict is resolved. If community members (those participating in a restorative justice process, other than the primary victim and offender, who have been impacted by the violence) also leave a restorative justice process believing that the violence was simply the result of a conflict that "got out of hand," they may not reflect on what contributes to or condones violence in their community. By failing to distinguish between conflict and violence, all of the participants risk missing opportunities to identify root causes of crime.

A consequence of violence becoming hidden is that it becomes absorbed into the fabric of the conflict, wherein victims can learn that they should perhaps be careful in the future about engaging in any conflict if they want to remain safe. This "lesson" is tied in with other possible messages they may interpret from a conflict-oriented restorative justice session. Victims may similarly conclude that:

- $\quad$ legal violations (for example, violations of rights to safety and security) are no more significant than the relational disagreements or communication problems that they are reduced to;

- $\quad$ violence, by itself, is an inappropriate topic for discussion in a justice process;

- the injuries sustained from the use of violence - physical damage, destruction of trust in an orderly world, ${ }^{22}$ shame, isolation, depression, and trauma - could all have been avoided if only the victim had been more skilled in conflict resolution strategies; and 
- the victim needs to share responsibility not only for the conflict escalating, but also for the violence occurring (and, in the future, for it not occurring).

One reason offenders may resist taking responsibility is that they do not want to concede their stance in the conflict that preceded the violence - and that should not be a requirement. The choice to use violence, if it is preceded by conflict, does not mean that their position in the conflict is invalid. Clarity about the focus on the violence leaves room for people to identify that the conflict may still be outstanding and in need of further attention.

This raises two more concerns about restorative justice practice, the first being that an offender's remorse about using violence can easily be interpreted as signalling their commitment to end their violence. This commitment may be unsuccessful unless additional supports (for example, participation in programs such as the Alternatives To Violence Project, counselling, therapy, and changes in environment) are identified and put into place. If remorse is seen as the benchmark of change, the likelihood of restorative justice practitioners inviting conversations about accessing these kinds of resources is questionable, at best, as will be the likelihood of inviting the deeper, more difficult discussions about both the internal and external factors informing the offender's use of violence. The second concern is that if restorative justice practitioners treat violence as conflict, it follows that resolving the conflict should result in the cessation of violent behaviour.

\section{INVITING REFLECTION AND DIALOGUE}

Our definitions and explanations [of violence] will determine our responses and policies what kinds of interventions are necessary or whether intervention is necessary at all. ${ }^{23}$

In order for restorative justice practitioners to prepare for working with violence, we believe that it is important for practitioners and programs to find ways to increase awareness and knowledge about violence and victimization, in addition to the information they already have about conflict resolution. Restorative justice practitioners and supporters should be engaging in dialogues about their work with conflict and violence in restorative justice processes. These dialogues could be enriched with valuable insights and research from other disciplines, recognizing that, while new information and theories may be challenging, they can also lead to new possibilities.

Training in restorative justice should include a focus on the particularities of working with people who have experienced and perpetrated various forms of violence, and how to create opportunities for people to engage in justice conversations that work towards addressing harm meaningfully.

We have found reflective questions like the following to be beneficial in helping to solidify these important distinctions and link explanations to practice. Discussing these questions has provided opportunities for us to uncover our foundational ideas and 
assumptions, mine the value of our experience, and clarify the focus of our restorative justice practice:

- How do I define conflict? How does this definition fit with other definitions of conflict?

- How do I define violence? How does this definition fit with other definitions of violence?

- What overlap do I see, and what distinctions do I make between conflict and violence?

- What kinds or forms of violence (if any) are involved in the cases that I work on?

- How comfortable am I working with violence in restorative justice? What aspects of working with violence disturb me?

- How might my discomfort about aspects of violence be affecting my work with victims, offenders, and community members?

- What time and space am I making for violence conversations in my restorative justice work?

- How might I be complicit in normalizing violence through the words that I use to describe violence?

- What might I need (for example, support, information, and training regarding the effects of violence) to work effectively with violence stories?

- How do my ideas/definitions about violence and conflict compare with those of my colleagues?

- What do programs or organizations need to do in order to support restorative justice work with cases involving violence?

\section{ConClusion}

Being witness to so many violence stories in peoples' lives has been a privilege for us and has provided us with a unique opportunity to think about the complexities of violence. For those who have been victims of violence, we have seen their willingness to speak not only about their struggle and grief, but also their resilience and strength. We have found that when we create time and space for people who have used violence to speak about the conflicts that they were a part of, conversations about their use of violence and what they carry responsibility for become clearer.

We believe it is important in a restorative justice process to explore the injustice and unique harm and impacts that violence has created, as well as the steps necessary to repair 
the harm to the extent possible through tangible and/or symbolic actions. In seeing violence as distinct from conflict the significance and unique nature of each can be honoured. Without an understanding that these concepts are distinct, participants' understanding of their safety can be diminished, and restorative justice might fall short of the promise it holds.

The intentional and active inquiry involved in defining the terms and concepts that frame restorative justice work may not result in hard, long-lasting definitions or theories (nor, perhaps, should it). However, the exercise in and of itself may result in a deeper understanding of these complicated ideas and, ultimately, more focused and deliberate restorative justice processes. 